\title{
The miR-338-3p involve in response to acute radiation syndrome by targeting DYRK2
}

\section{in Tibet minipig}

Yu-Jue Wang ${ }^{1}$, Min-Yue ${ }^{1 *}$, Kai Guo ${ }^{2}$, Shao-Jie Wu ${ }^{3}$, Yu-Guang Tian ${ }^{1}$

1 Department of Laboratory Animal Center, Southern Medical University, 1838\# Guangzhou

North Road, 510515, Guangzhou, Guangdong, China.

2 Department of Urology, Zhujiang Hospital, Southern Medical University, 253\# Industry

Road, 510282, Guangzhou, Guangdong, China

3 Department of Hemotology, Zhujiang Hospital, Southern Medical University, 253\# Industry

Road, 510282, Guangzhou, Guangdong, China.

*These authors contributed equally to this work

Keywords: miRNAs; intestines; Tibet minipigs; acute radiation syndrome

*Corresponding Author E-mail: jolly @ smu.edu.cn; 


\section{Summary statement}

In summary, our studies show that the miRNA signatures were in general X-ray irradiation dose-specific, and miR-338-3p can suppress HIC cell proliferation and induce HIC cell apoptosis by regulating the expression level of DYRK2 partially, which may be used as early immunological response biomarker for ARS in clinical research. However, more research is needed to evaluate the role of these and other miRNAs in small intestin in response to radiation administration.

\section{Abstract}

MiRNAs as tumor suppressor have been identified in variety of cancer, but the role of miRNAs involve in ARS (acute radiation syndrome) in Tibet minipig are poorly understood. Here, in order to study the relationship between miRNAs pattern and ARS, microarray chip technology was used for screening of ARS related miRNAs in Tibet minipig small intestine.Not castrated male Tibetan minipig were chose as animal model $(\mathrm{n}=54)$, and exposed to the total body X-ray radiation at $0,2,5,8,11,14 \mathrm{~Gy}(\mathrm{n}=9 /$ group), The total miRNA was extracted and hybridized to microarray chip. The HIC cell proliferation was evaluated by CCK8 assay, and the apoptosis was evaluated by flow-cytometric after X-ray irradiation. The athymic mice subcutaneous injection was used to research tumor formation. The bioinformatics tools and luciferase assay was applied to detect the relationship between miR-338-3p and its target. In total, 63 specific miRNAs were differentially regulated in the exposed small intestin tissues with 3, 24, 29, 25, and 32 miRNAs identified per dose-level (2, 5, 8, 11, and 14 Gy, respectively). MiR-338-3p was commonly regulated at 5, 8, 11, and 14 
Gy dose levels and was used for cell assay. MiR-338-3p can regulates. HIC cell proliferation and apoptosis after X-ray irradiation administration. DYRK2 is one of target of miR-338-3p and suppressed by X-ray irradiation administration. Our study first revealed the ARS associated miRNA signatures were generally dose-specific, and miR-338-3p involve in response to ARS by targeting DYRK2 and may be used as early immunological response biomarker for ARS research. 


\section{Introduction}

The influence of nuclear terrorism, nuclear contamination and nuclear radiation therapy to human survival, safety and health has become a hot topic of current medical research. Due to there is no obvious features of the symptoms of ARS, coupled with the clinical work by the personnel nuclear radiation damage is not very common, when in the situation of dealing with such a victim, most of clinical staff doesn't have a dear understanding on how to diagnosis the patient's injury and take what kind of active treatment measures. Although it is widely accepted that response to stressors is mediated by regulation of cell cycle progression and maintenance via gene transcription/translation and epigenetic mechanisms, global cellular responses required for cell survival remain unclear (Wu X et al., 2018). So, it is important to know more about which biological mechanisms play a key role after the total body X-ray radiation, and then provide optimal ARS treatment and minimize normal tissue injury.

MicroRNAs (miRNAs) are a novel class of small noncoding RNAs approximately 18-25 nucleotides in length that suppress gene expression by post-transcriptional mechanisms by targeting 3' untranslated regions (UTR) of gene mRNAs and have been shown to play important roles in many physiological and developmental pathways in a variety of organisms. A large amount of evidences show that miRNAs play important role in animal growth, development, and stress adaptations through regulating target genes expression (Aitken $\mathrm{S}$ et al., 2015; Ilnytskyy Y et al., 2008; Foronda D et al., 2014; Zacharewicz E et al., 2013). miRNAs can bind to the 3' UTR (3'untranslated region) of their target genes and regulate genes expression by promoting mRNA degradation as well as suppressing mRNA translation 
(Phillips JR et al., 2007; Simone NL et al., 2009; Mart’' 1nez G et al., 2011). A single miRNA may target multiple mRNAs and several miRNAs may be specific for the same target gene. The majority of human genes are regulated by different miRNAs, and miRNA play an essential role in fundamental cellular processes (Ono K et al., 2015; DU F et al., 2015; Wang $\mathrm{X}$ et al., 2015; Zhao $\mathrm{H}$ et al., 2015). In addition, miRNAs play an important role in the DNA damage response after physiological and pathological stressors, for instance in the response to reactive oxygen species and X-ray radiation (Liu B et al., 2015; Lee S et al., 2014; Xie L et al., 2014; Schook L et al., 2005;).

Compared with small mammals such as mice, large mammals models are superior in many aspects for the study of human diseases and pre-clinical therapies. The miniature pig is similar to human in anatomy, development, physiology, pathophysiology and disease occurrence, etc (Schook L et al., 2005). Although miniature pigs as animal models have been applied in several fields of study, it is rarely used as an animal model for acute radiation injury. The Tibet minipigs have a character of genetic stability, small size, early maturation, high fecundity. Therefore, the Tibetan minipigs could be a suitable animal model for the study of radiation diseases (Yue $\mathrm{M}$ et al., 2014). The small intestin is a late responding organ. However, in this late responding organ, cytokine cascades are activated and remain active throughout the phase of damage expression (Unver N et al., 2015; Kirsch DG et al., 2010 ).

Recently, several miRNAs have been documented to be involved in the radiation response. The expression of miR-34a and miR-194 were upregulated in spleen of the rats after radiation 
exposure (Xue Q et al., 2013; Koturbash I et al., 2007). Previous studies have shown that radionuclide administration has a divergent effect on transcriptional regulation in different normal tissues (Luzhna L et al., 2014; Sevan'kaev AV et al., 2002). However, X-ray radiation is a strong carcinogen that is able to initiate and promote tumor progression (Little J.B, 2000). Due to systemic regulation, these studies in vivo are important for illustrating the logical responses to the total body radiation exposure. The objective of this study was to explore the variation of the miRNA expression levels and screen out the specific miRNAs, and then analyze the mechanism of them on response to acute radiation syndrome in Tibet minipig.

\section{Results}

\section{Identification of altered miRNA expression associated with ARS}

In this study, we used an in vivo Tibetan minipig model to identify differentially regulated miRNAs in small intestin tissue under different X-ray radiation at $0,2,5,8,11,14 \mathrm{~Gy}$, respectively. In total, 63 specific miRNAs were identified at the different dose levels, with 3 , $24,29,25$, and 32 differentially regulated miRNAs in the 2, 5, 8, 11, and 14 Gy groups, respectively (Figure 1A). Few miRNAs were down-regulated after X-ray radiation. No down-regulated miRNAs were found at 2 and $11 \mathrm{~Gy}$, while miR-365 and miR-709 were down-regulated at $5 \mathrm{~Gy}$, only let-7k was down-regulated at $8 \mathrm{~Gy}$, and three miRNAs (miR-690, miR-1902, and miR-6239) were down-regulated at 14 Gy. No miRNAs were differentially regulated at all absorbed doses. The expression level of the majority of the regulated miRNAs varied between the absorbed doses. However, miR-338-3p was commonly and in general consistently regulated at 5, 8,11, and 14 Gy (Figures 1B\&1C), which showed a tendency towards increased expression level with increased absorbed dose. 


\section{MiR-338-3p is upregulated in HIC cells after radiation treatment}

The expression levels of miR-338-3p in HIC cells was assayed with qRT-PCR, miR-338-3p

expression in HIC cells after radiation treatment at 2 and 5 Gy was significantly increased

(Figure 2A\&2B) in comparison to control. Interesting, The expression levels of miR-338-3p was decreased with the increase of radiation dose. For the more, we hadn't harvested cells enough for qRT-PCR assay because of the adverse growth condition. Nevertheless, these findings support the hypothesis that upregulated miR-338-3p may play a key role in ARS.

\section{MiR-338-3p suppress cell proliferation and induce cell apoptosis in vitro}

The flow cytometer was used to evaluate the apoptosis rate of HIC cells transfected by miR-338-3p mimics and miR-338-3p inhibitors after radiation treatment. The results shown in Figure 2A\&2B demonstrated a significantly higher percentage of apoptotic cells for miR-338-3p mimics-treated cells compared to $\mathrm{NC}(\mathrm{P}<0.05)$, and a significantly lower percentage of apoptotic cells for miR-338-3p inhibitors-treated cells compared to $\mathrm{NC}(\mathrm{P}<0.05)$. For the more, we examined effect of miR-338-3p mimics and miR-338-3p inhibitors on cell proliferation after radiation treatment. CCK8 assay showed that growth of HIC cells was affected by the transfection of miR-338-3p mimics and miR-338-3p inhibitors (Figure 3C). These results indicate that radiation treatment and miR-338-3p can suppress the growth and induce apoptosis in HIC cell.

\section{DYRK2 is a target of miR-338-3p}

DYRK2 belongs to a family of protein kinases whose members are presumed to be involved 
in cellular growth and development (Mimoto R et al., 2013). In this study, DYRK2 was forecasted as a target of miR-338-3p by bioinformatics analysis (Figure 4A). The luciferase reporter assay showed that miR-338-3p suppressed the luciferase activity of the wild type but not the mutant 3'-UTR in HEK-293 cells (Figure 4B). Moreover, treatment with the miR-338-3p mimics or (and) radiation decreased the protein level of DYRK2, and in contrast, treatment with the miR-338-3p inhibitors promoted the protein level of DYRK2 in HIC cell (Figure 4C\&4D). The results showed that DYRK2 is a direct target genes of miR-338-3p and irradiation administration can regulate the expression of DYRK2 mediated by miR-338-3p.

\section{MiR-338-3p inhibits tumor growth in athymic mice}

HIC cells were transfected with miR-338-3p mimics and miR-338-3p inhibitors and then injected subcutaneously into male athymic mice, and weighed the tumor 8 weeks later. Compared with the control group, the tumors of miR-338-3p inhibitors group grew more quickly, and on the contrary, miR-338-3p mimics significantly decreased the tumor volume and weight compared with the control group (Figure 5A\&B). These results indicated that miR-338-3p can suppress tumor growth in vivo.

\section{MiR-338-3p suppress expression of Dyrk2 in vivo}

The expression of DYRK2 was assayed by western blot and immunohistochemistry. The results suggested that miR-338-3p mimics can significantly inhibit protein expression of DYRK2. On the contrary, miR-338-3p inhibitors could significantly promote protein expression of DYRK2 (Figure 5C, 5D, 5E). The findings further support the hypothesis that 
miR-338-3p may affect the growth of HIC cells in vivo and involve in response to acute radiation syndrome by altering DYRK2 protein expression.

\section{Discussion}

Cell growth, cell cycle, apoptosis rate and DNA damage repair of mammals may be affected in the case of radiation exposure (Li S et al., 2013; Jin H et al., 2015; Liu C et al., 2013). In recent years, Although more and more evidences have confirmed that non-coding RNA may render cell stress responses, the mechanism inducing and stimulating apoptosis is very complex and still unknown. MiRNAs play an important role in cell stress responses, DNA repair, apoptosis and cell cycle control and members of these families were found consistently differentially regulated in the present study. So, the specific expression of the miRNAs may involve in response to radiation exposure. The small intestins are one of the major sites of side effects of X-ray radiation therapy of intestinal tumors due to the high uptake of the radiopharmaceutical in this organ (Suman S et al., 2015). Basic insight into how normal small intestin tissues responds to X-ray radiation is therefore vital for the continued optimization of therapy with this radiopharmaceutical. In the present study, aberrant miRNA expression patterns were investigated in Tibet minipig small intestin tissue after X-ray radiation administration. Our findings demonstrate common miRNA deregulation among all the studied absorbed doses as well as dose-specific miRNA deregulation. miRNA families previously reported to be frequently associated with radiation exposure were detected. The results showed that exposure produced a strong immunological response on small intestin tissue. The use of microarray analysis to investigate the miRNA response allows for a comprehensive view of the biological effects following exposure. A previous study has described the poor 
reproducibility between microarray and miRNA-seq data when miRNAs were associated with overall survival in ovarian cancer profiles (Wan YW et al., 2014). However, the mechanism of miRNAs involve in response to ARS of large mammal is a very complicated question, affected by many factors including biological characteristics of own cells. Although ARS is rare, it is a complex and medically challenging disorder that has the potential for large-scale incidence on the battlefield or in conjunction with a domestic terrorist attack (Bonnaud $\mathrm{S}$ et al., 2010; Kirsch DG et al., 2010; Driák D et al., 2008). Researchers have identified a number of non-coding RNA as radiation response markers but the mechanism is far from clear (Gao F et al., 2015; Cha HJ et al., 2014; Yuan W et al., 2014). In this study, we investigated the role of miR-338-3p, a non-coding RNA deemed associated with ARS. In early stage of this study, we found that miR-338-3p was commonly and in general consistently regulated at 5, 8, 11, and 14 Gy (Figures 1B\&1C), which showed a tendency towards increased expression level with increased absorbed dose, and this may help us to make a breakthrough. To further evaluate the role of miR-338-3p involve in response to ARS, we designed experiments in which we changed the expression level of miR-338-3p so as to detect the various aspects of biology of HIC cell. Our research showed that miR-338-3p expression was significantly upregulated in HIC cell after irradiation administration. Then, we increased the expression of miR-338-3p, HIC cell proliferation was suppressed and the apoptosis rate in HIC cells was induced significantly. These results indicate miR-338-3p plays a crucial role in response to ARS and may become a new biomarker for ARS research. In order to explore molecular mechanism of miR-338-3p in the proliferation and apoptosis of HIC cell, we investigated the miR-338-3p's potential target in HIC cell. DYRK2 is an important protein in cell proliferation and 
differentiation. Bioinformatics analysis and luciferase activity assay demonstrated that DYRK2 is a direct target genes of miR-338-3p. The miR-338-3p mimics can significantly decreased protein expression level of DYRK2 in the HIC cells.

\section{Materials and Methods}

\section{Tibetan minipigs and radiopharmaceutical preparation}

A total of 54 not castrated male Tibetan minipigs (8-15 months, purchased from the Laboratory Animal Center of Southern Medical University of China) were used for total body irradiation (TBI). The average weight and height of the pigs were $22.36 \pm 7.74 \mathrm{~kg}$ and $82.88 \pm 9.13 \mathrm{~cm}$, respectively. The pigs were caged in aseptic rooms and were randomly divided into six groups containing nine animals each. They were anesthetized with ketamine (0.05 ml/kg i.v.) before radiation exposure. One control group $(\mathrm{n}=9)$ was not exposed to radiation. Five treatment groups ( $n=9$ for each group) were irradiated with single doses of 2 , 5, 8, 11 or 14 Gy TBI using an 8-MV X-ray linear accelerator (Elekta Synergy Platform, ELEKTA Ltd, Sweden) at a dose rate of $255 \mathrm{cGy} / \mathrm{min}$ for all experimental groups. The standardized uptake value and the marrow nucleated cell number data were initially collected at 6, 24 and $72 \mathrm{~h}$ and were then collected on Days 5-60 post-TBI at 5-day intervals. The Tibetan minipigs were killed by cardiac puncture after data collection and the small intestins were dissected, and then were immediately snap-frozen inliquid nitrogen and stored at $-80^{\circ} \mathrm{C}$ until use. The experimental protocol was approved by Institutional Animal Care and Use Committee of the Southern Medical University of China. 


\section{MicroRNA microarray}

The total RNA was isolated from Tibetan minipig small intestin tissue under different X-ray radiation at $0,2,5,8,11,14$ Gy using Trizol reagent (Takara, Japan) according to the instructions. The quantity of RNAs were evaluated using $2 \%$ formaldehyde-agarose gel electrophoresis and spectrophotometry (Bio-Rad, Hercules, CA, USA). Exiqon LNA MicroRNA Array was used to profile miRNA expression performed by KangCheng Bio-Tech Inc (Shanghai, China).

\section{Bioinformatics methods and luciferase assay}

TargetScan and Diana-Microt software were applied to predict miR-338-3p putative targets, the target predicted by the two software were screened out, and then the target gene DYRK2 was screened preliminarily. The wild-type of DYRK2 3'-UTR was cloned from Tibetan minipig cDNA library with the primers in table 1 . Mutations of miR-338-3p binding site was introduced by site-directed mutagenesis using a fast mutation kit (Takara, Japan). The PCR fragment was jointed into psiCHECK-2 vector downstream of the firefly luciferase coding region within Sgf I and Pme I (Takara, Japan). psiCHECK-2-control was used as internal control.

\section{Cell culture and transfection}

HIC cells (Human intestinal cancer cell lines) were ordered from CICLR(Beijing, China).

Cells were cultured with DMEM (Hyclone, USA) and supplemented with 10\% fetal bovine serum (Hyclone, USA), 100U/ml penicillin and $100 \mathrm{mg} / \mathrm{ml}$ streptomycin (Sigma, USA), at 
$37^{\circ} \mathrm{C}$, in $5 \% \mathrm{CO} 2$ incubator (Thermo, USA). Cells were seeded in a $100 \mathrm{~mm} 2$ plate at $5 \times 106$

cells per plate 24 hours before transfection. Cells were transfected using $10 \mathrm{ml}$ of Lipofectamine 2000 (Invitrogen) and $1 \mathrm{mg}$ of miR-338-3p mimics or miR-338-3p inhibitors mixed with $1 \mathrm{mg}$ of empty vector in $10 \mathrm{ml}$ of Opti-MEM (Sigma, USA). Cells were cultured in transfection media for 6 hours then in McCoy's 5A media with 10\% FBS. 24 hours after the completion of transfection, cells were harvested for radiation treatment .

\section{Radiation treatment of HIC cells}

Radiation processing method for tumor cells commonly used in similar studies was applied: HIC cells suspension with cells adjusted to $1 \times 106 / \mathrm{ml}$, was inoculated in 6-well culture plate. After short-term culture, the cultured cells were irradiated with linear accelerator. The condition was vertical 6MV-X-ray irradiation and 0,2, 5, 8, 11, $14 \mathrm{~Gy} / \mathrm{min}$ dose rate. During irradiation, the bottom of the culture plate was added $1.5 \mathrm{~cm}$ tissue equivalent filer and the source skin distance was $100 \mathrm{~cm}$. The irradiation was carried out twice and the irradiation interval was $72 \mathrm{~h}$.

\section{Stem-loop quantitative real time PCR analyses}

The total RNA was isolated using Trizol reagent (Takara, Japan) following the instructions.

Mature miRNAs were converted into cDNA by stem-loop reverse transcription using specific stem-loop primers(Table 1). The qRT-PCR analyses for miRNAs were performed by ABI 7500 real-time PCR machine (USA). The miRNAs expression levels were normalized and quantified by U6 RNA as described previously. 


\section{Cell proliferation assays}

The Cell Proliferation Reagent Kit I (Roche, USA) was used to evaluated the cell proliferation. HIC cells were harvested $72 \mathrm{~h}$ after transfection and radiation treatment, and grown in the 48 -well plates (5000 cells/well). Cell proliferation was recorded every $24 \mathrm{~h}$ according the manufacturer's protocol.

\section{Flow-cytometric analysis of apoptosis}

The cells were harvested $2 \mathrm{~d}$ after transfection by trypsinization and radiation treatment, then washed twice with washing buffer, and resuspended in binding buffer at $1 \times 105$ cells $/ \mathrm{ml}$. Cells double stained by FITC and PI underwent flow cytometry for apoptosis detection. All cells were divided into living cells, necrosis cells and apoptotic cells.

\section{Athymic mice assay}

Male athymic mice (4 weeks old, Animal Center of Southern Medical University) were acclimated for one week under sterile conditions. Collected cells transfected with miR-338-3p mimics or miR-338-3p inhibitors from the 6 well plates, and washed the cells with PBS rendering resuspended cells of $1 \times 107$ cells/ml. Subcutaneously inject $0.1 \mathrm{ml}$ of suspension cells to mice, 10 mice per group. 12 weeks later the mice were sacrificed, and the tumors were dissected, photographed and weighed, and then were immediately snap-frozen inliquid nitrogen and stored at $-80^{\circ} \mathrm{C}$ until use. The study was approved by the Ethics Committee of the Southern Medical University. 


\section{Western blotting}

The samples were harvested using RIPA buffer (Beyotime, China) supplemented with Complete Protease Inhibitor Cocktail (Roche) and PMSF (Roche). Approximately 50 $\mu$ g of the protein extraction was subjected to $10 \%$ SDS-PAGE, then transferred to nitrocellulose membrane using the iBlot transfer system (Sigma) and incubated with antibodies (Cell Signaling); Quantity One v4.4.0 software (Bio-Rad, USA) was used to assay optical density of the DYRK2 bands and results were normalized to the expression of $\beta$-actin.

\section{Immunohistochemistry}

To evaluate the expression of immune cell antigens using immunohistochemistry, $3 \mu \mathrm{m}$ tissue sections of paraffin-embedded, formalin-fixed tissues were deparaffinized in xylene and rehydrated in a series of graded ethanol. Endogenous peroxidase activity was blocked by immersing sections in $3 \% \mathrm{H} 2 \mathrm{O} 2$ for 5 minutes. The sections were blocked in $10 \%$ fetal bovine serum for 10 minutes at room temperature and then incubated with primary antibodies to DYRK2 (Cell Signaling) for 60 minutes of staining. Immunostaining was carried out using the IHC Kit (Beyotime, China) for 15 minutes according to the manufacturer's protocol and finally visualized with diaminobenzidine. In addition, sections were then counterstained with hematoxylin. The nomal tissue served as the positive control.

\section{Statistical analyses of data}

All statistical analyses were performed using SPSS version 19.0 (SPSS Inc. Chicago, IL) and 
GraphPad Prism version 5.0(GraphPad, San Diego, Calif) softwares. P value less than 0.05 was considered statistically significant.

\section{Acknowledgments}

We are grateful to all participants of the group at Institute of Comparative Medicine \& Laboratory Animal Center.

\section{Competing Interests}

The authors declare that there is no conflict of interest financial or otherwise associated with this submission.

\section{Author Contributions}

Conceived and designed the experiments: YJW. Performed the experiments: YGT,. Analyzed the data: YM and SJW. Wrote the paper: YGT, YJW; YGT Edited and revised manuscript. All authors read and approved the final manuscript.

\section{Funding:}

This work was supported by the Science and Technology Planning Project of Guangdong

Province of China (Grant No. 2017A030303019, to YGT; Grant No. 2016A030303008, to

YM; No. 2017A030310100 to KG, No.2018030310286, to YJW), Natural Science Foundation

of Guangdong Province (Grant No. 2017A030313192, to YGT ), Medical science and

Technology Research Funding of Guangdong Province (Grant No. A2017124, to YGT; Grant 
No.A2016255, to YJW).

\section{References:}

Wu X, Ding N, Hu W, He J, Xu S, Pei H, Hua J, Zhou G, Wang J. (2014). Down-regulation of BTG1 by miR-454-3p enhances cellular radiosensitivity in renal carcinoma cells. Radiat Oncol. 9:179.

Aitken S, Magi S, Alhendi AM, Itoh M, Kawaji H, Lassmann T, Daub CO, Arner E,

Carninci P, Forrest AR, Hayashizaki Y; FANTOM Consortium, Khachigian LM,

Okada-Hatakeyama M, Semple CA. (2015). Transcriptional dynamics reveal critical roles for non-coding RNAs in the immediate-early response. PLoS Comput Biol. 4 :e1004217.

Ilnytskyy Y, Zemp FJ, Koturbash I, Kovalchuk O. (2008). Altered microRNA expression patterns in irradiated hematopoietic tissues suggest a sex-specific protective mechanism. Biochem Biophys Res Commun. 377 : 41-45.

Foronda D, Weng R, Verma P, Chen YW, Cohen SM. (2014). Coordination of insulin and Notch pathway activities by microRNA miR-305 mediates adaptive homeostasis in the intestinal stem cells of the Drosophila gut. Genes Dev. 28 :2421-2431.

Zacharewicz E, Lamon S, Russell AP. (2013). MicroRNAs in skeletal muscle and their regulation with exercise, ageing, and disease. Front Physiol. 4 :266.

Phillips JR, Dalmay T, Bartels D. (2007). The role of small RNAs in abiotic stress. FEBS Lett. $581: 3592-3597$.

Simone NL, Soule BP, Ly D, Saleh AD, Savage JE, Degraff W, Cook J, Harris CC, Gius D, Mitchell JB. (2009). Ionizing radiation-induced oxidative stress alters miRNA 
expression. PLoS One. 4: e6377.

Martínez G, Forment J, Llave C, Pallás V, Gómez G. (2011). High-throughput sequencing, characterization and detection of new and conserved cucumber miRNAs. PLoS One. 6 :e19523.

Ono K, Horie T, Nishino T, Baba O, Kuwabara Y, Kimura T. (2015). MicroRNAs and High-Density Lipoprotein Cholesterol Metabolism. Int Heart J. 56 :365-71.

DU F, Wu H, Zhou Z, Liu YU. (2015). microRNA-375 inhibits osteogenic differentiation by targeting runt-related transcription factor 2. Exp Ther Med. 10 :207-212.

Wang X, Qiu W, Zhang G, Xu S, Gao Q, Yang Z. (2015). MicroRNA-204 targets JAK2 in breast cancer and induces cell apoptosis through the STAT3/BCl-2/survivin pathway. Int J Clin Exp Pathol. 8 :5017-5025.

Zhao H, Zhang C, Hou G, Song J. (2015). MicroRNA-H4-5p encoded by HSV-1 latency-associated transcript promotes cell proliferation, invasion and cell cycle progression via p16-mediated PI3K-Akt signaling pathway in SHSY5Y cells. Int J Clin Exp Med. $8: 7526-7534$.

Liu B, Liu M, Wang J, Zhang X, Wang X, Wang P, Wang H, Li W, Wang Y. (2015). DICER-dependent biogenesis of let-7 miRNAs affects human cell response to DNA damage via targeting p21/p27. Nucleic Acids Res. 43 :1626-1636.

Lee S, Choi E, Cha MJ, Hwang KC. (2014). Looking into a conceptual framework of ROS-miRNA-atrial fibrillation. Int J Mol Sci. 15 :21754-21776.

Xie L, Zhou J, Zhang S, Chen Q, Lai R, Ding W, Song C, Meng X, Wu J. (2014). Integrating microRNA and mRNA expression profiles in response to radiation-induced injury 
in rat lung. Radiat Oncol. $9: 111$.

Schook L, Beattie C, Beever J, Donovan S, Jamison R, Zuckermann F, Niemi S, Rothschild M, Rutherford M, Smith D. (2005). Swine in biomedical research: creating the building blocks of animal models. Anim Biotechnol. 16 :183-90.

Yue M, Tian YG, Wang YJ, Gu Y, Bayaer N, Hu Q, Gu WW. (2014). Associated analysis of single nucleotide polymorphisms found on exon 3 of the IGF-1 gene with Tibetan miniature pig growth traits. Genet Mol Res. 13 :1263-1269.

Unver N, Coban G, Onaran OI, Kunduz E, Arslan A, Malya FU, Hasbahceci M. (2015). Co-existence of acute appendicitis and inflammatory myofibroblastic tumor of the small intestine: A case report. Ann Med Surg (Lond). 4 :217-220.

Kirsch DG, Santiago PM, di Tomaso E, Sullivan JM, Hou WS, Dayton T, Jeffords LB, Sodha P, Mercer KL, Cohen R, Takeuchi O, Korsmeyer SJ, Bronson RT, Kim CF, Haigis KM, Jain RK, Jacks T. (2015). P53 controls radiation-induced gastrointestinal syndrome in mice independent of apoptosis. Science. 327:593-596.

Xue Q, Sun K, Deng HJ, Lei ST, Dong JQ, Li GX. (2013). Anti-miRNA-221 sensitizes human colorectal carcinoma cells to radiation by upregulating PTEN. World J Gastroenterol. 19 :9307-9317.

Koturbash I1, Boyko A, Rodriguez-Juarez R, McDonald RJ, Tryndyak VP, Kovalchuk I, Pogribny IP, Kovalchuk O. (2007). Role of epigenetic effectors in maintenance of the long-term persistent bystander effect in spleen in vivo. Carcinogenesis. 28 :1831-1838.

Luzhna L, Kovalchuk O. (2014). Low dose irradiation profoundly affects transcriptome 
and microRNAme in rat mammary gland tissues. Oncoscience. $1: 751-762$.

Sevan'kaev AV, Lloyd DC, Edwards AA, Moquet JE, Nugis VY, Mikhailova GM, Potetnya OI, Khvostunov IK, Guskova AK, Baranov AE, Nadejina NM. (2002). Cytogenic investigations of serious overexposures to an industrial gamma radiography source. Radiat Prot Dosimetry. 102 :201-206.

Little J.B. (2002). Radiation carcinogenesis. Carcinogenesis, 21 :397-404.

Mimoto R, Taira N, Takahashi H, Yamaguchi T, Okabe M, Uchida K, Miki Y, Yoshida K. (2013). DYRK2 controls the epithelial-mesenchymal transition in breast cancer by degrading Snail. Cancer Lett. $339: 214-225$.

Li S, Chou AP, Chen W, Chen R, Deng Y, Phillips HS, Selfridge J, Zurayk M, Lou JJ, Everson RG, Wu KC, Faull KF, Cloughesy T, Liau LM, Lai A. (2013). Overexpression of isocitrate dehydrogenase mutant proteins renders glioma cells more sensitive to radiation. Neuro Oncol. 15 :57-68.

Jin H, Yoon HE, Lee JS, Kim JK, Myung SH, Lee YS. (2015). Effects on g2/m phase cell cycle distribution and aneuploidy formation of exposure to a $60 \mathrm{~Hz}$ electromagnetic field in combination with ionizing radiation or hydrogen peroxide in 1132 nontumorigenic human

Liu C, Gao P, Xu SC, Wang Y, Chen CH, He MD, Yu ZP, Zhang L, Zhou Z. (2013). Mobile phone radiation induces mode-dependent DNA damage in a mouse spermatocyte-derived cell line: a protective role of melatonin. Int J Radiat Biol. 89 :993-1001.

Suman S, Kallakury BV, Fornace AJ Jr, Datta K. (2015). Protracted upregulation of leptin and IGF1 is associated with activation of PI3K/Akt and JAK2 pathway in mouse intestine after ionizing radiation exposure. Int J Biol Sci. 11 :274-283. 
Wan YW, Mach CM, Allen GI, Anderson ML, Liu Z. (2014). On the reproducibility of TCGA ovarian cancer microRNA profiles. PLoS One. 9 :e87782.

Bonnaud S, Niaudet C, Legoux F, Corre I, Delpon G, Saulquin X, Fuks Z, Gaugler MH, Kolesnick R, Paris F. (2010). Sphingosine-1-phosphate activates the AKT pathway to protect small intestines from radiation-induced endothelial apoptosis. Cancer Res. 70 :9905-9915.

Kirsch DG1, Santiago PM, di Tomaso E, Sullivan JM, Hou WS, Dayton T, Jeffords LB, Sodha P, Mercer KL, Cohen R, Takeuchi O, Korsmeyer SJ, Bronson RT, Kim CF, Haigis KM, Jain RK, Jacks T. (2010). p53 controls radiation-induced gastrointestinal syndrome in mice independent of apoptosis. Science. 327 :593-596.

Driák D, Osterreicher J, Vávrová J, Reháková Z, Vilasová Z. (2008). Morphological changes of rat jejunum after whole body gamma-irradiation and their impact in biodosimetry. Physiol Res. 57 :475-479.

Gao F, Chen S, Sun M, Mitchel RE, Li B, Chu Z, Cai J, Liu C. (2015). MiR-467a is upregulated in radiation-induced mouse thymic lymphomas and regulates apoptosis by targeting Fas and Bax. Int J Biol Sci. 11 :109-121.

Cha HJ, Kim OY, Lee GT, Lee KS, Lee JH, Park IC, Lee SJ, Kim YR, Ahn KJ, An IS, An S, Bae S. (2014). Identification of ultraviolet B radiation-induced microRNAs in normal human dermal papilla cells. Mol Med Rep. 10 :1663-1670.

Yuan W, Xiaoyun H, Haifeng Q, Jing L, Weixu H, Ruofan D, Jinjin Y, Zongji S. (2014). MicroRNA-218 enhances the radiosensitivity of human cervical cancer via promoting radiation induced apoptosis. Int J Med Sci. 11 :691-696. 
Table 1 Primer sequences of products expression

\begin{tabular}{|c|c|c|}
\hline Gene name & Primer name & Primer sequence \\
\hline \multirow[t]{3}{*}{ miR-338-3p } & RT primer & 5' CTCAACTGGTGTCGTGGAGTCGGCAATTCAGTTGAGAGGTCGTAGTC 3' \\
\hline & forward primer & 5’ ACACTCCAGCTGGGGTTGTTTTAGTG 3' \\
\hline & reverse primer & 5' CTCAACTGGTGTCGTGGA 3' \\
\hline \multirow{2}{*}{ U6 } & forward primer & 5' CTCGCTTCGGCAGCACA 3' \\
\hline & reverse primer & 5' AACGCTTCACGAATTTGCGT 3' \\
\hline \multirow[t]{2}{*}{ Dyrk2r } & RT prime & radom primer \\
\hline & reverse primer & 5' CCCTGGCGCTTCTTAGCATTT 3' \\
\hline \multirow[t]{3}{*}{$\beta$-actin } & RT primer & radom primer \\
\hline & forward primer & 5' CTGGGACGACATGGAGAAAA 3', \\
\hline & reverse primer & 5'AAGGAAGGCTGGAAGAGTGC 3' \\
\hline \multirow[t]{2}{*}{ Dyrk2-3'UTR } & forward primer & 5' GCTCACGTCCCCTGATGCTGG 3' \\
\hline & reverse primer & 5' AAGCATTGTCCTCATGTATTT3' \\
\hline
\end{tabular}




\section{Figure Legends}

Figure 1. Number of specific expressed miRNAs. (A,B) Distribution of differentially regulated miRNAs in small intestine tissues from Tibet minipig after X-ray irradiation administration, resulting in absorbed dose to small intestin of 0-14 Gy. Positive numbers indicate up-regulation, while negative numbers indicate down-regulation. (C) The expression of miR-338-3p were detected in small intestin tissues from Tibet minipig after X-ray irradiation administration. *indicate $P<0.05$

Figure 2. Effect of X-ray irradiation administration on HIC cell growth and miR-338-3p expression. (A) The Effect of X-ray irradiation administration from 0-14 Gy on HIC cell growth. (B) The expression of miR-338-3p were detected in HIC cell after X-ray irradiation administration. *indicate $P<0.05$. Scale bars, $100 \mu \mathrm{m}$.

Figure 3. Effect of miR-338-3p on cell apoptosis and proliferation. (A,B) Apoptotic rates were detected by flow cytometry in $\mathrm{HIC}$ cells. NC, normal control; R, radiation administration; M, transfected with miR-338-3p mimics; I, transfected with miR-338-3p inhibitors; RM, radiation administration and transfected with miR-338-3p mimics; RI, radiation administration and transfected with miR-338-3p inhibitors. Compared with $\mathrm{NC},{ }^{*} P<$ 0.05; compared with $\mathrm{R},{ }^{*} P<0.05$. (C) HIC cells was transfected with miR-338-3p mimics or miR-338-3p inhibitors, and CCK8 assays were performed to determine the proliferation in HIC cells. Experiments were performed in triplicate.

Figure 4. DYRK2 is a direct target of miR-338-3p in HIC cells. (A) Wild type DYRK2-untranslated regions (3'-UTR) (WT) or Mutated DYRK2 3'-UTR (Mut) of DYRK2 sequence. (B) HEK-293T cells were co-transfected with miR-338-3p /miR-NC with WT/Mut 
3'-UTR of DYRK2. Relative luciferase activity was evaluated. (C,D) HIC cells transfected with miR-338-3p mimics or miR-338-3p inhibitors, and the expression level of DYRK2 was detected by western blot. GAPDH was used as a control. Experiments were performed in triplicate. $* p<0.05$, compared with control.

Figure 5. The effect of miR-338-3p on tumorigenesis in vivo. (A) miR-338-3p mimics or miR-338-3p inhibitors was transfected into HIC cells, which were injected in male athymic mice $(n=10)$, respectively. (B)Tumor weights were calculated after injection 8 weeks. (C,D) Western blot was performed to detect the expression of DYRK2 in tumor nodule. $\beta$-actin protein was used as an internal control. *indicate $P<0.05$. (E) Immunohistochemistry of DYRK2 expression in tumor nodule. Data are expressed as $\%$ positive nuclei $\square \pm \square$ SEM (n $\square=\square 6$ ). A two-tailed unpaired t-test was performed, *indicate $P<0.05$. 

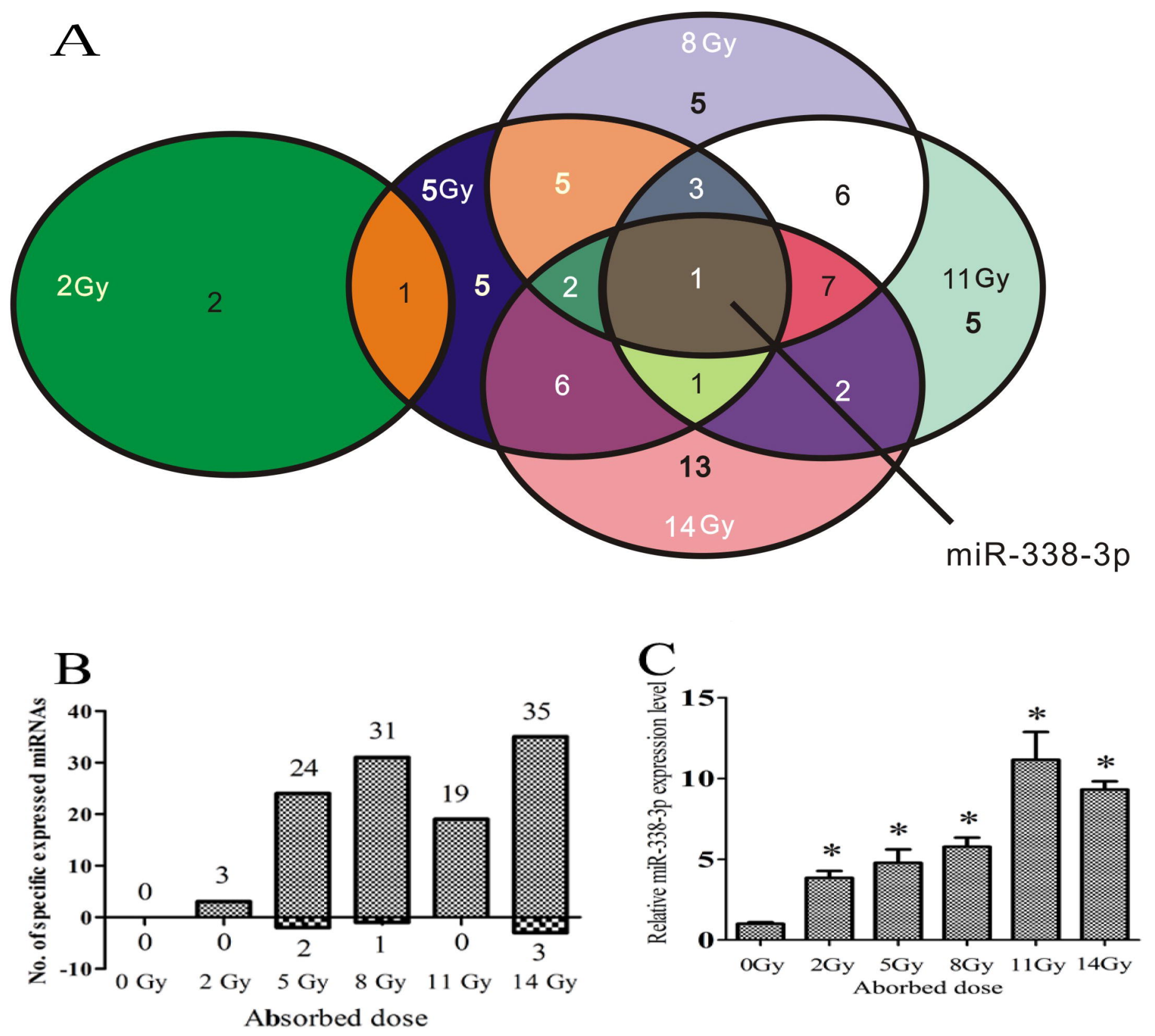
Absorbed dose 
A
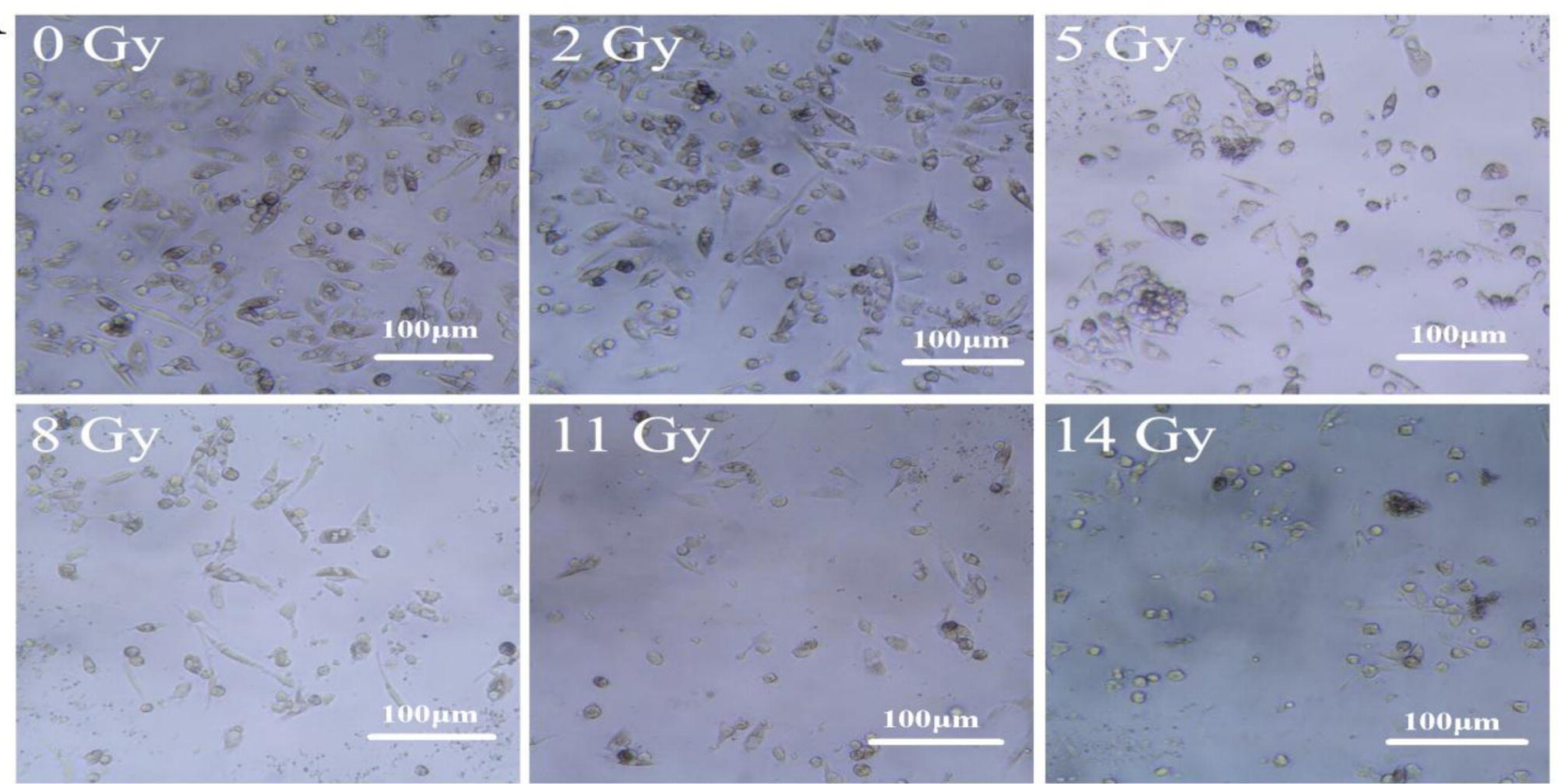

B

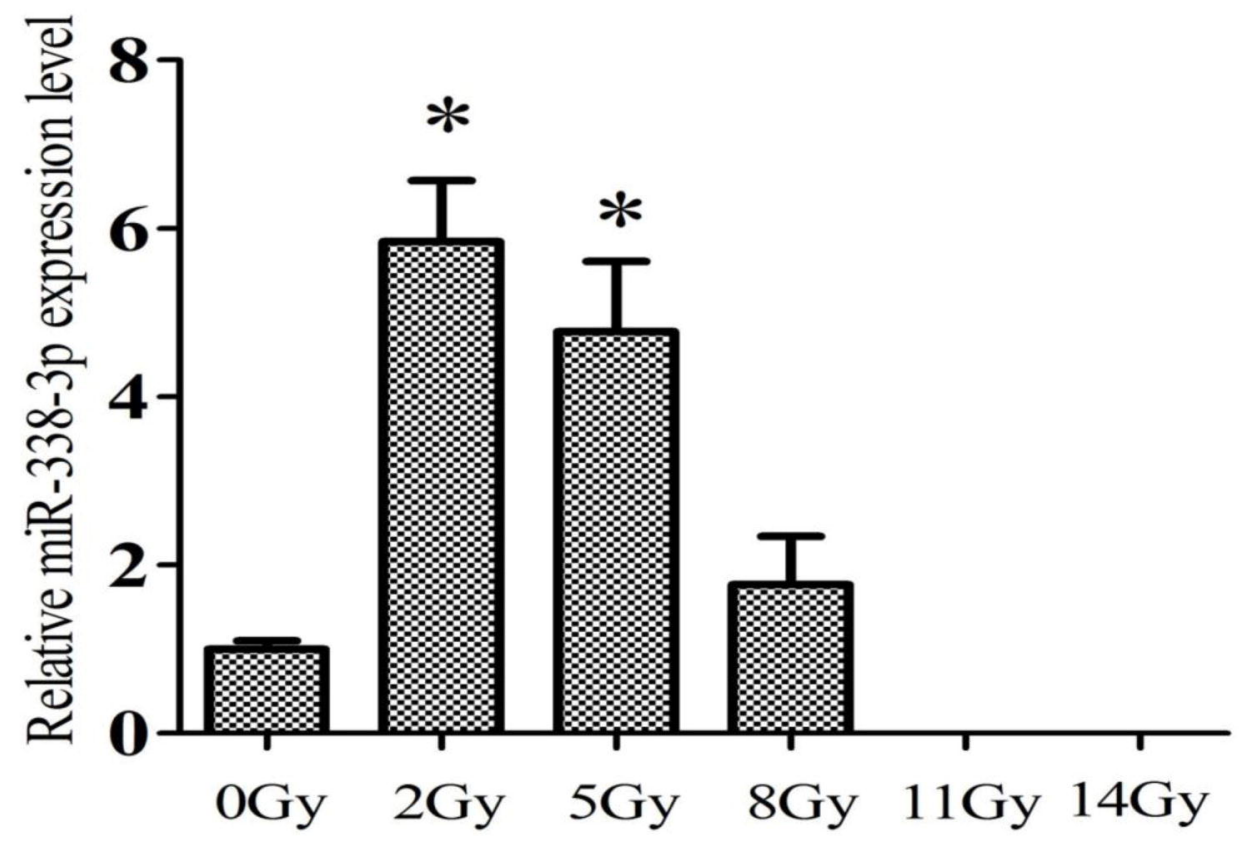



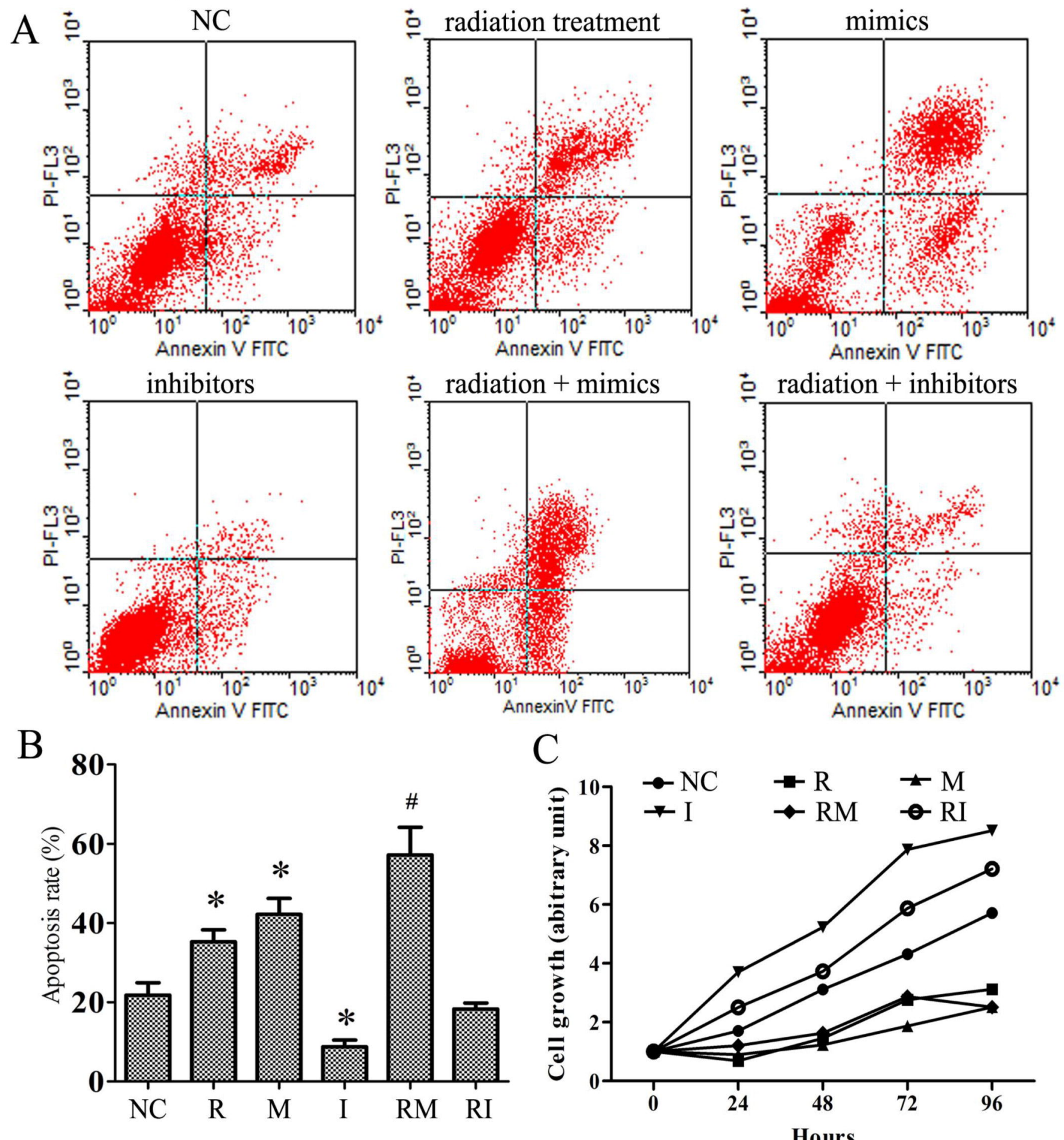
DYRK2 WT 3' UTR 5 '...gcuCACGUCCCCUGAUGCUGGu ... 3' || | | || || || || miR-338-3p 3' guuGUUUUAGUGACUACGACCu 5' DYRK2 2 mut $3^{\prime}$ UTR $5^{\prime}$...gcuCCCGUCCCACAGUACCAGu .... $3^{\prime}$

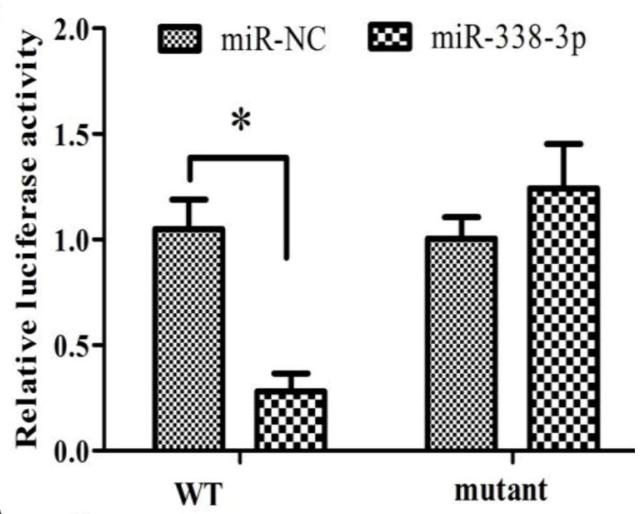

$\mathrm{C}$

$\begin{array}{llllll}\mathrm{NC} & \mathrm{R} & \mathrm{M} & \mathrm{I} & \mathrm{RM} & \mathrm{RI}\end{array}$

Dyrk2

$\beta$-actin
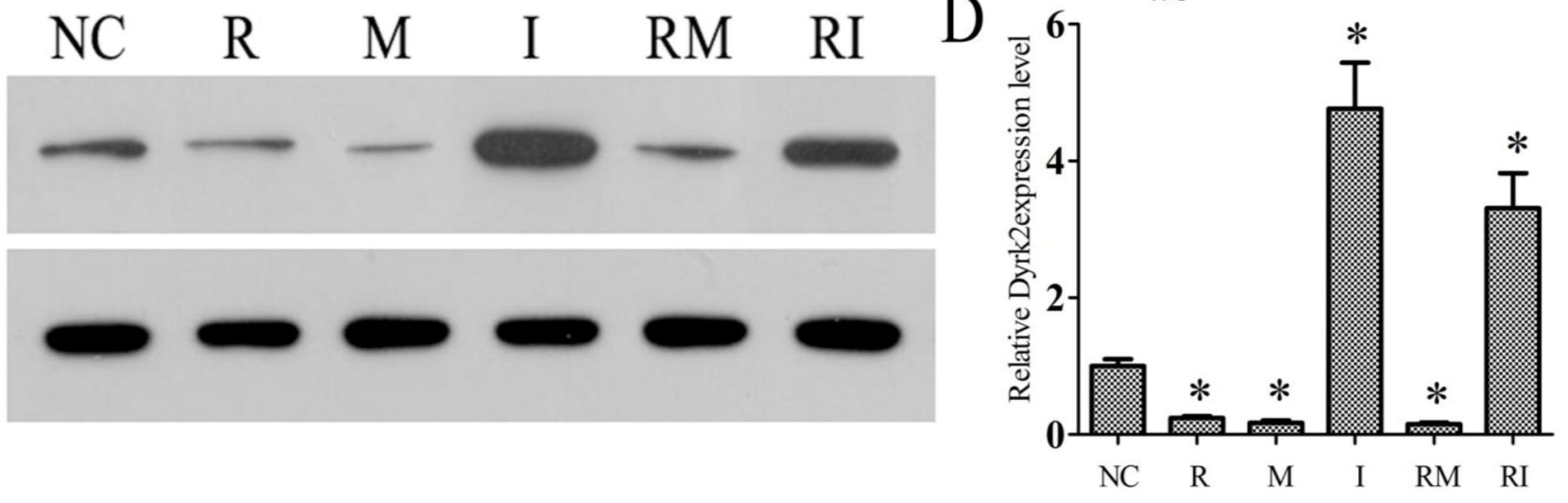


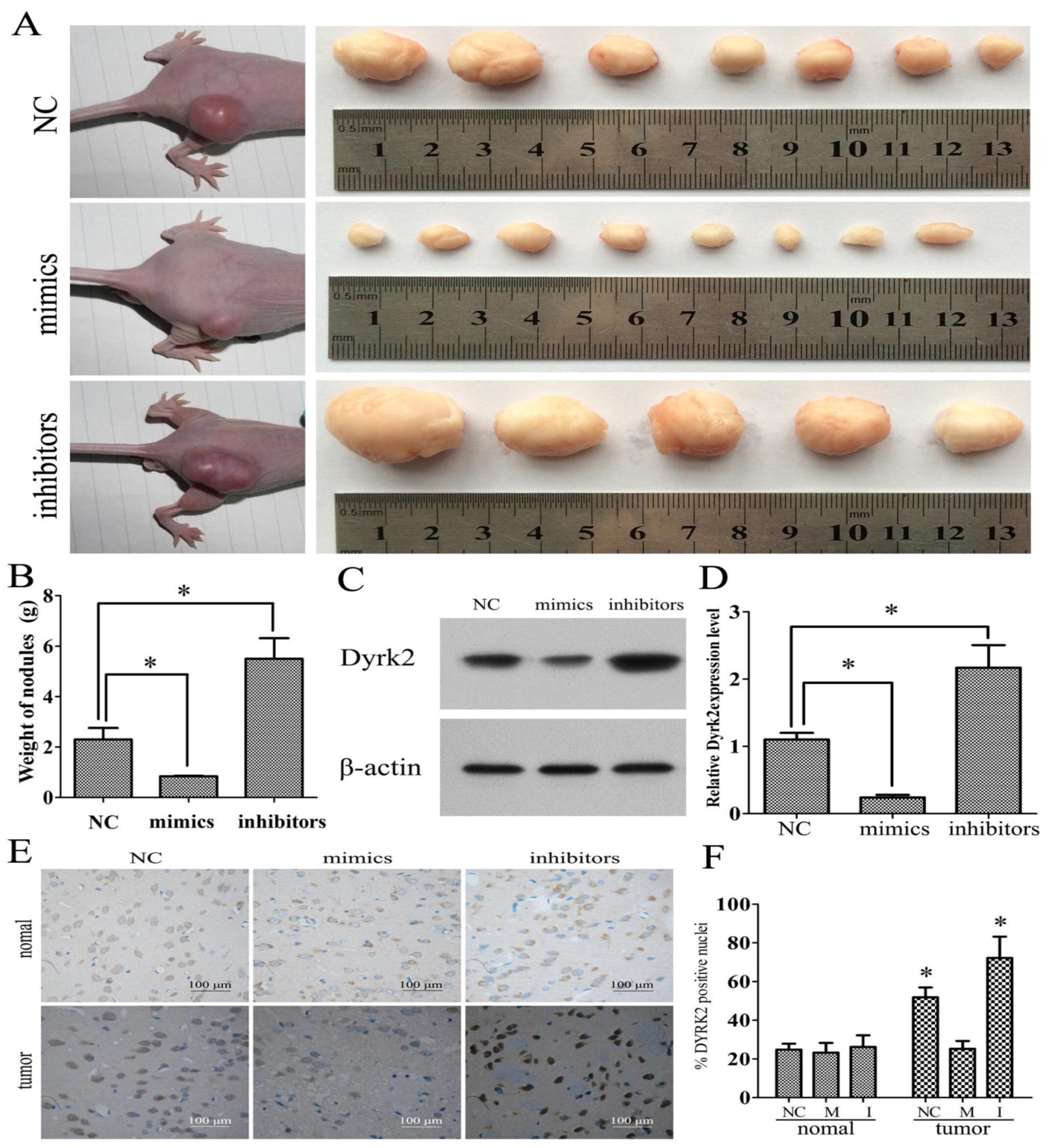

